\title{
Marketplace Spirituality: \\ The challenges for the New Age retailer
}

by

Keri Davies

Paul Freathy*

* Corresponding Author

Institute for Retail Studies

University of Stirling

Stirling

FK9 4LA

Tel: +441786467410

Fax +44 1786465290

Corresponding author e-mail: j.p.freathy@stir.ac.uk 


\title{
Marketplace Spirituality: \\ The challenges for the New Age retailer
}

\begin{abstract}
The consumers of New Age spirituality products have been said to be involved in a form of 'pick and mix' religion or to be browsing in a 'spiritual supermarket' which emphasises borrowing from a wide variety of cultures. The paper details the different physical and virtual channels through which consumers may access goods and services. Retailers who serve this market are typically independent traders and face many of the challenges that are characteristic of the small business sector. The term 'New Age' is identified as applying to a broad range of retailers who attempt to occupy different market positions. The research however identifies considerable product overlap between these retailers and suggests that the market displays limited differentiation. As this paper is an exploratory study it finally sets out a series of research themes for future work.
\end{abstract}

Keywords: Spirituality, retailing, small business, religion 


\section{Introduction}

"one can practice Chinese meditation while listening to Andean relaxation music and burning Indian incense. One can go on a yoga retreat in the Caribbean, enjoy aromatherapy massages and eat a strictly macrobiotic diet based on Japanese foods. Through the very combination of the public sphere of alternative health and the global marketplace, the individual is empowered to create his or her own unique strategy for living in the modern world " (Lau, 2000: 13)

Interest in what has often been termed 'New Age' spirituality ${ }^{i}$ has been burgeoning (e.g., Rose, 1998; Heelas and Woodhead, 2005) and the resulting significant growth in the range of spiritual offerings has emphasised the role of the market (Redden, 2002; 2005). Considerable attention has been given to questioning the ethics of 'selling' spirituality, the practices of those engaged in the provision of spiritual products and services and the manner in which consumers engage in a market based spirituality (e.g., Jocks, 1996; Carrette and King, 2005; Kale 2004; Rindfleish 2005). The packaging and repackaging of spiritual theorems suggests a commodification of values which reduces diverse spiritual traditions to "brand names selling essentially the same product with slightly different packaging”.. (Jones, 1997: 17). Despite such criticisms, consumers continue to be attracted to and engage in the spiritual marketplace (Redden, 2002; 2005).

Although increased attention has been devoted to understanding spirituality and spiritual practices, there has been little discussion into how the retail market has responded. Focus has primarily been upon those who consume spirituality rather than upon those who service the demand. As a consequence, there remain questions over how the market is defined, how it operates and how it is evolving. The objective of this paper is to partially rectify this anomaly by providing an exploratory investigation into the retail spirituality market. Although the sector remains fragmented and predominantly occupied by small, independent businesses, the paper highlights a variety of different channels through which spirituality is delivered in the marketplace and highlights apparent inconsistencies in the 
strategic positioning of different retail providers. In addition, the paper draws attention to the considerable gaps in our current understanding of retail spirituality and details the primary themes that should guide a future research agenda.

To achieve this, the paper is divided as follows; first, various definitions relating to spirituality are provided and the factors that have led to the increased demand for spiritual products and services are identified. The retail response is then examined within the context of the marketplace. Finally, a series of conclusions are drawn that both assist our understanding of spiritual retailing as well as highlight the gaps in our current research knowledge.

\section{The Spirituality Consumer}

Roof (1999) links the emergence of the spirituality industry in the United States to social conditions and the perceived inability of existing institutions to answer people's moral, religious and ethical concerns and questions (see also Binkley, 2003). However because of its subjective and personal nature, gaining a consensus of what actually comprises spirituality, remains difficult (Cawley, 1997; Redden, 2002; Hart and Brady, 2005; Holak, 2008; Kale 2004), Definitions remain plentiful and a number of common themes emerge. These include the meaning and purpose of life, creativity and relationships (McSherry \& Cash, 2004) as well as connectedness, inner strength and peace (Tanyi, 2002). A key aspect of all definitions of spirituality, however, appears to be a focus on the 'self' (Bellah et al, 1996: 221), even though this was often not the original intention of the faiths or traditions involved (Gould, 2006; Thomas, 2009).

Kale (2004) notes the individual nature of spirituality and the tendency to create a belief system from other religious and spiritual traditions. Individuals identify and choose those elements they consider to be most relevant for their own personal needs (Aupers and 
Houtman, 2006; Kale 2004). This variety seeking approach runs contrary to traditional religious belief, or life-as-religion, which is characterised by the worship of one or more related deities supported by a defined doctrine (Redden, 2002). Such a 'pick and mix' approach' has been criticised for its superficial nature. Labels such as the 'spiritual market place' (Bruce, 2002; Turner, 2004) and the 'spiritual supermarket' (Mathews, 2000) have been applied to the process whereby individuals eclectically arrive at a belief system that will be meaningful for them (Kale 2004).

Other commentators have argued that researchers have often been too quick to attribute superficiality and insincerity to beliefs that do not fit within notions of 'authentic' spirituality. "Although these qualities are clearly evident in the production and marketing of much "New Age' merchandise, the spiritual supermarket continues to entice and supply real people, sincere and serious people, who are genuinely seeking a greater sense of meaning of and purpose" (Mulcock, 2001: 170). Mulcock argues that the forms of cultural borrowing found in New Age spirituality reflect not just the role of consumerism in the global marketplace but also the primacy of creativity in New Age thought (Hanegraff, 1996).

Commercialising a faith-based phenomenon is not a new concept as evidenced by the historical arguments over the sale of religious artifacts. Starrett (1995) however notes that the onset of mass production techniques and the requirements of a market driven economy have led to the proliferation of objects that can aid an individual's spiritual journey (see also Thomas, 2009). Similarly Kale (2004) argues that the rise of web based spirituality has accelerated the level of market fragmentation and provided individuals with unprecedented access to New Age goods and services. The pursuit of a customised spiritual pathway has therefore been aided by the growth in products such books, videos and CDs, the emergence of cheaper sites of production, such as China as well as an increase in the number of self-help groups, retreat centres, seminars and workshops (Possamai, 2003; Zaidman, 2007b). 
The ethics of 'selling' the sacred and who buys the wide array of products now on the market has been examined by a number of commentators (e.g., Starrett, 1995; Carrette and King, 2005; Rindfleish, 2005). Gould (2006) for example, draws a distinction between 'spiritual materialism' and spirituality. The former represents individuals who consume spirituality superficially in a similar way to other types of consumption, whilst the latter refers to those who are pursuing a path of enlightenment or fulfilment. Inevitably there will be overlap between these two categories and it is therefore suggested that spiritual consumption has varying degrees of engagement ranging from the casual or material through to the enlightened or fulfilled. Irrespective of the motivations for spiritual market engagement, there is evident demand for spiritual goods and services which in turn, has created a marketplace through "a peripheral network of retailers, producers and distributors...presumed to share a common understanding of commerce as a distinct moral enterprise" (Binkley, 2003: 239).

\section{Spirituality in the Marketplace}

Consumers of spirituality may access a broad range of goods and services through a variety of different types of channel. The products offered can vary considerably as they reflect the different market positions of each provider. To better understand how the spirituality market is configured the following section provides a brief contextual overview.

\section{Channel choice}

Table 1 illustrates the range of different providers that currently operate in the market. Due to the low barriers to entry and exit, the spirituality market would appear to comprise numerous independent traders, on-line retailers and training providers. Offering the opportunity for people to engage in the self- expression of their spiritual identity, retailers range from complementary medicine providers to witchcraft stores and from on-line tarot 
readers to at-home clairvoyant service providers. As with Christian consumerism (Thomas, 2009: 68-69), the growth of both stores and on-line media providers may make it easier for goods and services to circulate amongst participants, as well as offering 'New Age' alternatives for the fulfilment of many daily needs in areas such as food, clothing and cosmetics. Consumers are therefore no longer limited to a single channel; for example, individuals seeking a Psychic Consultation have the option of attending a residential retreat, visiting a Psychic Fair, having a reading via the telephone or through a Skype connection.

[Table 1 about here]

But popularity can also bring its own problems. First, if the demand for particular goods and services can no longer be spatially defined, retailers will be required to compete outside the immediacy of their local market. This in turn raises questions as to whether spirituality retailers are required to adopt a multi-channel approach in order to remain competitive and how this will affect their market position. Whether the spirituality marketplace is primarily cost driven or whether other factors such as convenience or reputation influence channel choice is uncertain. The reputation of the spiritual provider may appear to hold some importance as the following extract from an internet forum illustrates:

"... the best way to get a genuine medium reading is to go to your local spiritualist church. if you go to one of their services, you will find they hold a short service, entailing the Lords prayer and a couple of Hymns, and then a medium does about an hour of clairvoyancy, .... The spiritualist church also, do private one to one readings, which does cost money, I have had private readings, one cost me $£ 15+£ 1$, the other reading cost me $£ 25$. The different prices were down to the mediums not the church, the dearer one was because he is a bit of a celeb having worked on stage with top tv mediums and the other medium was a lady who does them from time to time especially for the church, ..... might I also add, that you are always best going to the spiritualist church, for readings as these people are genuine, they have to be approved and pass test, otherwise they wouldn't be allowed to do readings there, also they are a lot cheaper. Please don't bother with mediums off the internet apart from the fact they are dear, they could be con artist, also don't get ones out the paper for the same reason, if you find a medium that's not from the spiritualist church, always try to go to one who people you know have recommended.... " Forum.sofeminine.co.uk/ 
The above quote would also suggest an awareness on the part of the consumer that accessing spirituality via different channels can carry different elements of risk. The importance of branding as a risk reducing exercise has been well documented in the academic literature (De Chernatony and Riley, 1998) but its influence in the New Age retail market remains largely unexplored. In recent years the spiritual marketplace has witnessed a number of individuals gaining high profile, public recognition. For example, Doris Stokes achieved an international reputation as a clairvoyant, while others such as Russell Grant and Derek Acorah have achieved almost celebrity status through their numerous media appearances and television shows. Although less well known outside spirituality circles, individuals such as Doreen Virtue and Diana Cooper, have successfully positioned themselves as named brands and developed their own ranges of Angel and Tarot cards. However it would also appear that many products categories such as crystals, aroma oils, incense and joss sticks provide little evidence of national or international brand identity. Given the fragmented nature of the spirituality sector and in the absence of a clear market leader, it is difficult to measure the extent to which individual retailers have attempted to create and develop a brand identity.

Second, while many of these goods and services continue to be offered through specialist retailers or on-line providers, over the past two decades a number of 'spiritual' products have been incorporated into the retail offer of more conventional retailers. Ezzy (2003; 2006) for example, highlights the spread of witchcraft books from specialist channels into more mainstream stores and other outlets. In these studies, products such as spell books aimed at young teenage or pre-teen females were found in supermarkets and toy stores in Australia. Similarly, Heelas and Woodhead (2005: 68-69) found that in their local town in England around forty-five per cent of stores carried products that signalled, encouraged or facilitated holistic spirituality, compared to just seven per cent providing goods related to life- 
as-religion. These included many High Street chains such as Boots, Sainsbury's, Lush, the Body Shop and WH Smith.

\section{Products: marking the stages of the life spiritual}

Table 2 attempts to categorise those spirituality goods and services offered by different types of store based retailers. The table is based on the study of a small sample of 31 retail outlets in Scotland whose primary product mix consisted of items with a spiritual dimension, along with a number of other retailers who did not class themselves as New Age but offered a selection of spiritual products as part of their overall merchandise mix. The latter included clothes stores, gift shops as well as national grocery multiples. The categories used are based upon how the stores defined themselves either on their web-sites or in their in-store promotional literature.

[Table 2 about here]

What becomes apparent from this Table is the diverse range of retailers servicing the spiritual needs of consumers. A number of stores defined themselves as New Age or specialists in "Mind, Body and Spirit" (MBS). Others considered themselves to have a more defined position in the market and focused upon specialist niches such Paganism, Occultism or Wiccanism ${ }^{\mathrm{ii}}$. The broad appeal of spirituality means that the market has attracted those retailers who specialise in spirituality products and services as well as those whose offer comprises a relatively small or inconsequential part of the merchandise mix. This distinction not only applied to national multiple operators such as Tesco (who sold a selection of Spirituality magazines) but also retailers such as a fetish outlet whose primary focus was upon underwear, collars, whips, chains and role playing clothes. Although, the latter store 
offered Tarot and crystal ball readings this was supplemental to the core business and main merchandise assortments.

What is also evident from Table 2 is that despite being categorised as a particular specialist or niche provider, there appears to be considerable product overlap between different categories of retailer. At one end of the spirituality spectrum, the market comprises specialist Occult / Witchcraft stores selling Ouija Boards, Cauldrons and Pentagrams. At the other end of the market, the research identified a New Age store that sold Unicorn themed items, fairy doors and baby gifts. Despite occupying seemingly polarised market positions, both stores offered Tarot cards, relaxation CDs and healing crystals. This level of product overlap was significantly more pronounced when comparing Pagan / Wiccan, Occult / Witchcraft and a number of New Age stores. What distinguishes an Occult store from a Witchcraft retailer, whether there are identifiable differences between Pagan and Wiccan stores and what differentiates a New Age from an MBS outlet are amongst some of the unanswered questions raised in this research.

Table 2 would also seem to reinforce the notion that the financial demands of the retail marketplace may undermine the opportunity to adhere to a specific market position. The product convergences identified amongst these spirituality retailers may be indicative of a series of compromises that businesses have been required to make in order to generate sufficient consumer footfall.

This popularisation of New Age beliefs and the consequent product commodification that has accompanied it, has led to criticism from some New Age commentators. For example, Coco and Woodward (2007) argue that the wider availability of products such as spell kits and fairy wands has served to both trivialise and sentimentalise Pagan beliefs. Moreover, it is argued that the growth of popular TV programmes such as Charmed and Buffy 
has not only misrepresented and undermined the authenticity of Paganism, it has had a negative impact upon the formation of its cultural identity.

\section{Staff : The Customer, the Shopkeeper and the Moral Compass}

It is likely that most of the retailers providing spirituality goods and services look beyond just the spiritual value of the products on offer to emphasize the spiritual dimension of the organization itself (Frost and Egri, 1994). This is representative of the increasing interest in the role of spirituality in transforming organizational behaviour and its links to social and ethical behaviour (Neal et al, 1999). There are also clear links to the ideals of the proponents of the counter-cultural revolution of the 1960s and 1970s (Cox, 1994; Binkley, 2003).

However, as Hamilton, (2000) notes, the absence of binding doctrines and of any overall leadership within the spirituality sector has implications for the way in which New Age thoughts are disseminated and practiced. The unregulated nature of the spirituality marketplace means that the moral compass guiding the retail market is a self-regulating one. On the one hand, Zaidman (2007a) stresses the requirement for individual integrity amongst New Age retailers as their customers view them as experts. As such, shopkeepers are required to display significant product knowledge, to be able to comment on the suitability of individual items with respect to personal need, and to give advice on a range of spiritually related matters (referred to by Zaidman as the provision of a 'culture guide'). On the other hand, Zaidman and others have reported that many customers of New Age stores hold unrealistic expectations of products, and expect relationship problems to be solved through the simple purchase of a sacred ornament.

This highlights the potential for improved consumer welfare, as well as an opportunity for potential exploitation. Theoretically, customers seeking guidance could be 'sold' products in order to capitalise on their vulnerability. Zaidman (2007a) countered some of this 
scepticism by pointing to the role of many participants as both producers and consumers of spiritual goods and services. She argued that most of the sellers populating the market truly believe in what they do and thus have a moral dimension to the motivation for their participation.

Zaidman (2007a) also found that in addition to the store owner, store staff often reported that they were in effect acting in the role of counsellors, relating less to the goods and services on offer and more to the underlying issues or problems that had brought the customer to the store in the first place. She referred to this position as one of a 'lay consultant' because the staff often reported that all they could do was listen and provide a sympathetic audience. Heelas and Woodhead, (2005: 105) suggest such roles might attract female workers into the sector as they are more willing and better able to hear and recognize the life-issues brought to them by a (normally female) practitioner or fellow-participant.

Also from a research perspective, what remains unclear is whether the influence and role of the shopkeeper and staff extends beyond that of expertise and spiritual guidance. If there is no over-riding control or authority to proscribe or direct, or even any consistent 'style book' which can be consulted, then not only can a believer in Hinduism with Wicca tendencies construct his own combination of beliefs and consumption practices but he could conceivably also influence a range of others through the goods sold in the store and/ or through the ways in which they are displayed and juxtaposed. If this assumption is correct then the notion of a 'spiritual supermarket' (Mathews, 2000) should not necessarily evoke a sense of superficiality and materialism, rather the store can come to represent a physical manifestation of the personal and spiritual beliefs of the owner and those who work within the store.

The emphasis on the spiritual journey also suggests that few retailers enter the market in order to make money. Despite the potential for exploitation noted above, in many cases 
owners reported that such dialogue/ interaction did not lend itself to market-based outcomes and this may partly explain why they were found to have relatively low expectations in terms of the remuneration they were likely to receive (Mulcock, 2001). This is not an unusual position for small businesses as they often do not prioritise growth (Paige and Littrell 2002); entrepreneurs often display the dual goals of personal fulfilment as well as business endeavour (Dobbs and Hamilton 2007). Thus, Van Gelderen and Jansen (2006) noted that a central theme running through many studies of the formation of small businesses is the need for some form of independence and autonomy. Workers in small retail stores have been found to derive satisfaction from nature of the work and the store environment rather than just from money (Bent and Freathy, 1997). In particular, individuals like to decide upon their own strategy and working methods as well as regulate their own time. As a consequence, many firms display idiosyncratic peculiarities that distinguish them from larger organisations (Beaver and Prince, 2004).

\section{Shops as experiences/shops as sacred places}

Retailers in the spirituality marketplace tend to exemplify this statement, for them, a New Age store can be seen as an expression of a set of spiritual values and so becomes a means of setting out those values and of making them available to other like-minded persons. Zaidman (2007a: 366-9) notes that around half of her sample saw their store solely as a spiritual or alternative centre. The other half saw the store as both a spiritual centre and a business - but with low or lowered expectations in terms of the financial remuneration they were likely to get from the store. The business is a means to an end, both in terms of the owner's experience and in terms of the ability to influence others.

Lower expectations do not however make spirituality retailers immune from the demands of the marketplace. For example, decisions over stocking and merchandising 
require a degree of market forecasting and, reflecting the pressures upon many small businesses, may require operators to expand their range of goods and services to include some 'popular' footfall drivers that can cross-subsidise the original purpose of the business.

Hamilton (2000: 193) used longitudinal data to show that new areas of spiritual practice and new products may be introduced over relatively short time periods in order to attract new customers. For example, aromatherapy and colour therapy have long been popular with consumers while Reiki and dragons have gained significant followings more recently. The centre of New Age 'taste makers' is in the United States (Zaidman, 2007b) and their views and purchases are disseminated globally through magazines, books, television appearances, blogs and websites. To reflect the dynamic nature of the marketplace, local shopkeepers must buy and display goods based on customer demand and recommendations from suppliers as well as according to their own beliefs and experiences. Nevertheless, many products will be delisted subsequently if they fail to find a local market or to provide an adequate financial return. The extent to which the values and principles of New Age retailers need to be compromised by the financial imperatives that govern most for-profit organizations, remain largely unexplored in the academic literature.

Product stocking policies may however extend beyond a simple set of margin related decisions as some store owners see everything that they carry as having an element of meaning, which in turn determines whether or not the items are offered for sale. Zaidman (2007a) noted that some objects even took on a 'life of their own' and came to be seen as a major part of the store's atmosphere. Objects such as large natural crystals and religious sculptures can become talismanic and signify the spiritual nature of the store itself. Such products were 'adopted' by customers to the point where they could not be sold - either because the trader felt that it would upset the customers or because their perceived effect on 
the store layout was an increase in the levels of 'positive energy' within the trading environment.

The layout and design of spirituality stores have received almost no academic attention. Zaidman (2007a) saw the entrance to a New Age outlet as a transition from the secular or profane to the spiritual, with notice boards and other markers delimiting the 'outside' from the 'inside'. This ritual separation signals a break with the external environment (Dion and Arnould, 2011) which helps to prevent the 'outside' from contaminating the experience and the goods offered to customers. Thus it suggests that the social-psychological significance of store design may be higher in this sector compared to other retail forms (Markin et al, 1976).

\section{Defining a Future Research Agenda}

New Age retailers appear to exhibit many of the features of other small businesses. The literature suggests that for many it is a move from being, first, a committed consumer, then a provider of advice and finally a commercial operator. It provides an opportunity to run a business based on one's own interests which can be used also as a career route by some of the high proportion of women involved in this area.

This move however takes us into more mainstream issues of organizational growth and development. How the business manages its expansion over time, its access to finance and the need to differentiate itself in the market are issues common to many small retailers. The number of customers able to sustain a hobby are seldom large enough to maintain a viable business. Like many small traders, there is a need to construct a product range that will be meaningful over time, while at the same time coping with shifting consumer tastes and directions. Is a retailer able to service a specific clientele and maintain a distinct market position or do market demands elicit a broader more eclectic approach when determining the product offer? 
The limited research into the New Age marketplace suggests that consumers have access to a variety of retail channels and a wide range of goods and services. The fragmented nature of the market and the low barriers to entry may also explain why a number of mainstream retailers include a 'spiritual' offer in their merchandise assortments. Although consumers may benefit through increased choice and availability, such findings also point to a highly competitive retail market. The subsequent strategic and operational response from New Age firms remains unclear. Whether it has prompted a move into multi-channel retailing, a focus upon service rather than price or an attempt to establish a brand identity is the subject of further study.

Moreover, further research may help establish the factors that drive and influence the evolution of the spirituality market. A number of business related themes therefore emerge from this exploratory overview of the retail spirituality market.

\section{Theme One: Ownership Classification and Strategy}

Proposition 1a: The spirituality retail sector is primarily dominated by independent operators who conform to contemporary definitions of a small business. These retailers experience strategic and operational challenges that are consistent with and characteristic of, other small enterprises.

Proposition 1b: Given the link between the shopkeeper's own spiritual beliefs and the manner in which the firm is organised and run, a typology of spirituality providers should focus upon beliefs, motivations and intentions rather than upon business activities.

Proposition 1c: Store owners will have limited management training and there will be little evidence of formal strategic planning. Strategies are likely to be short term piecemeal and 
intuitive. As a consequence, the direction of the business will have emerged over time and be more consistent with a 'realised' than an 'intended' strategy.

\section{Theme Two: Values and Beliefs}

Proposition 2a: Although there are likely to be numerous reasons put forward for operating a new age outlet, the desire for autonomy, independence and the ability to exercise control over one's working environment will be the primary motives for store owners.

Proposition 2b: New Age retailers will place priority upon non financial objectives. Maximising sales revenue and profitability will not be primary goals and intrinsic factors such as personal well being and the ability help others will be considered more important.

Proposition 2c: New Age retailers are most likely to get satisfaction from their work when they are able to sell goods or provide advice in their areas of interest. They are likely to be most dissatisfied or uncomfortable when they see themselves as 'ordinary' shopkeepers, having to sell a wide range of goods just to keep the shop financially viable.

Zaidman (2007a) identified that the advice and counselling provided to New Age customers reflected a belief system that also manifested itself in other channel relationships (Neal et al, 2003). Therefore:

Proposition 2d: New Age retailers will be committed to reflecting their spiritual beliefs and values in how they manage staff, suppliers and customers. 
Proposition 2e: Employees who work in new age outlets will derive satisfaction from working in a small store environment and from the nature of the work itself. They will also reflect the spiritual beliefs and values of the store and / or its owner.

Proposition 2f: Employees will possess a range of empathetic skills, reflect a concern for consumer welfare and frequently be required to provide guidance and counselling as well as sales advice.

Proposition $2 g$ : The motivations and perceived benefits that stem from working within a new age store will differ between male and female employees.

\section{Theme Three: Merchandising and Operations}

Research into Christian consumption has suggested that many customers are seeking an environment where they are able to immerse themselves in their faith (Bellah et al 1985; Thomas 2009). Whilst many of the New Age shops had a core range of goods and services in one particular area e.g. Wicca, they appear unable to offer a totally immersive environment. This raises issues of the degree to which the provision of products aimed at other beliefs may affect the firm's market positioning.

Proposition 3a: The design and layout of the retail store will reflect the owners own spiritual viewpoint and hold a degree of social-psychological significance both for the shopkeeper and customers. 
Proposition 3b: As particular spirituality products increase in popularity New Age retailers are required to stock items of merchandise that drives footfall rather than reinforces the core positioning of the store.

Proposition 3c: Shopkeepers find it difficult to incorporate many new goods and products into their belief systems. Whilst these may be desired by customers and provide financial benefits they are sold only at the cost of personal dissonance or dissatisfaction.

The development of internet and mobile retail channels is also driving major changes in this market. Initially seen primarily as a mechanism for providing information, these channels are now offering a deeper range of many New Age goods as well the possibility of one-to-one consultations or advice at any time of the day and from any location. This is both driving the development of 'one-stop' shops that can cater to a wide range of beliefs and allowing the part-timer or hobbyist to reach a wider audience without the need to actually open a physical shop.

Proposition 3d: Many existing New Age retailers will seek to develop a presence in these non-store channels but they will find it difficult to make themselves distinctive. As the market evolves, there is likely to be a split between the development of larger providers based around well-known brands and smaller specialists.

\section{Theme Four: Customer Loyalty and the Moral Compass}

It has been suggested that the shopping environment and the interaction with the shopkeeper are as important as the goods themselves. Potential customers are more likely to return to New Age retailers that demonstrate both a depth of product and of knowledge/ sympathy 
towards a small set of core beliefs. In contrast, a shop that has no perceived core of beliefs is unlikely to generate much loyalty.

Proposition 4a: Again, as suggested in much of the literature on small business retailing, those New Age traders that survive are most likely to have a strong relationship with their customers. They will support their customers' spiritual journeys, offering advice and new directions as and when required. Their own spiritual quest will allow them to continue to operate as a spiritual guide to others.

\section{Conclusions}

Consumer interest in 'New Age' spirituality and spiritual practices has grown significantly in recent years. Many individuals have sought to achieve some form of personal enlightenment through the selection of various religious practices, ideas and beliefs. The retail market has responded to this demand and consumers may now access the spiritual marketplace through a variety of different channels. Perhaps surprisingly therefore, there has to date, been limited academic attention on how the New Age market is configured, how it is structured and how it operates. The aim of this paper has been to partly rectify this omission by providing a context for the further study of New Age retailing, an understanding of the primary channels through which consumers can access the market as well as defining a future research agenda.

Unlike established religions such as Christianity, those who seek some form of enlightenment through the acquisition of spiritual goods and services appear to display no clear consumption patterns. The brief overview of the market suggests that Spirituality or New Age retailing represents an umbrella term under which a loose amalgam of different stores are attempting (more or less successfully) to occupy a variety of different market positions. At the same time, there appears to be some difficulty in differentiating between 
types of new age provider with considerable overlap between merchandise categories. Although any claims of 'confused positioning' (Porter, 1985) may be challenged through detailed empirical research, an understanding of the differences that exist between each provider is not yet apparent. Moreover, if the strategic and operational challenges that confront this sector of retail are to be fully understood, further detailed research again remains essential.

As may be expected from an exploratory investigation, this study has raised more questions than it has been able to answer. It is hoped however that this paper is seen as a starting point for continued investigation into marketplace spirituality and that the themes that have been identified remain worthy of further research. 


\section{REFERENCES}

Aupers, S. and Houtman, D. (2006). Beyond the Spiritual Supermarket: The Social and Public Significance of New Age Spirituality. Journal of Contemporary Religion, 21(2), 201222.

Beaver, G. and Prince, C. (2004). Management, strategy and policy in the UK small business sector: a critical review, Journal of Small Business and Enterprise Development, 11(1), 34 49.

Bellah, R.N., Madsen, R., Sullivan, W.M., Swidler, A. and Tipton, S.M. (1985). Habits of the Heart. Individualism and Commitment in American Life. Berkeley: University of California Press.

Bent, R. and Freathy, P. (1997).'Motivating the Employee in the Independent Retail Sector', Journal of Retailing and Consumer Studies, 4(3), 201-208.

Binkley, S. (2003). Cosmic profit: Countercultural commerce and the problem of trust in American marketing. Consumption, Markets \& Culture, 6(4), 231-249.

Bruce, S. (2002). God is Dead: Secularisation in the West. Oxford: Blackwell.

Carrette, J.R. and King, R. (2005). Selling spirituality: the silent takeover of religion. London: Routledge.

Cawley, N. (1997). An exploration of the concept of spirituality. International Journal of Palliative Nursing, 3(1), 31-36.

Coco, A. and Woodward, I. (2007). Discourses of Authenticity Within a Pagan Community: The Emergence of the "Fluffy Bunny" Sanction. Journal of Contemporary Ethnography, 36(5), 479-504.

Cox, C. (1994). Storefront Revolution. Food Co-ops and the Counterculture. New Brunswick, NJ : Rutgers University Press.

De Chernatony, L. and Riley, F. (1998). Modelling the components of the brand. European Journal of Marketing, 32, (11/12), 1074-90.

Dion, D. and Arnould, E. (2011). Retail Luxury Strategy: Assembling Charisma through Art and Magic. Journal of Retailing, 87(4), 502-520.

Dobbs, M. and Hamilton, R. (2007). Small business growth: recent evidence and new directions. International Journal of Entrepreneurial Behaviour and Research, 13(5), 296322.

Ezzy, D. (2003). New Age Witchcraft? Popular spell books and the re-enchantment of everyday life. Culture and Religion, 4(1), 47-65. 
Ezzy, D. (2006). White Witches and Black Magic: Ethics and Consumerism in Contemporary Witchcraft. Journal of Contemporary Religion, 21(1), 15-31.

Forum.sofeminine.co.uk/forum/loisirs3/_f446_loisirs3-Anyone-know-of-a-reputablemedium-clairvoyant-in-the-bournemouth-area.html (last accessed 4th October 2012)

Frost, P.J. and Egri, C.P. (1994). The Shamanic Perspective on Organizational change and Development. Journal of Organizational Change Management, 7 (1), 7-23.

Gould, S. J. (2006). Cooptation Through Conflation: Spiritual Materialism is not the same as Spirituality. Consumption, Markets and Culture, 9(1), 63-78.

Hamilton, M. (2000). An Analysis of the Festival for Mind-Body-Spirit, London Chapter 11 in: Sutcliffe, S. and Bowman, M. (eds) Beyond New Age. Exploring Alternative Spirituality. Edinburgh: Edinburgh University Press.

Hanegraff, W.J. (1996). New Age Religion and Western Culture. Esotericism in the Mirror of Secular Thought. Leiden: E.J. Brill.

Hart, D.W. and Brady, F.N. (2005). Spirituality and Archetype in Organizational Life.

Business Ethics Quarterly, 15 (3), 409-428.

Heelas, P. and Woodhead, L. (2005). The Spiritual Revolution. Why Religion is Giving Way to Spirituality. Oxford: Blackwell.

Holak, S. (2008). Ritual blessings with companion animals. Journal of Business Research, 61(5), 534-541.

Jocks, C.R. (1996). Spirituality for Sale: Sacred Knowledge in the Consumer Age. American Indian Quarterly, 20 (3/4), 415-431.

Jones, L.G. (1997). A Thirst for God or Consumer Spirituality? Cultivating Disciplined Practices of Being Engaged by God. Modern Theology, 13 (1), 3-28.

Kale, S. (2004). Spirituality, Religion, and Globalization. Journal of Macromarketing, 24 (2) pp. $92-107$.

Lau, K. (2000). New Age Capitalism. Making Money East of Eden. Philadelphia: University of Pennsylvania Press.

Markin, R.J., Lillis, C.M. and Narayana, C.L. (1976). Social-Psychological Significance of Store Space. Journal of Retailing 52(1), 43-55.

Mathews, G. (2000). Global Culture/ Individual Identity: Searching for Home in the Cultural Supermarket. London: Routledge.

McSherry, W. and Cash, K. (2004). The language of spirituality: an emerging taxonomy. International Journal of Nursing Studies, 41(2), 151-161. 
Mulcock, J. (2001). Creativity and Politics in the Cultural Supermarket: synthesizing indigenous identities for the r/evolution of the spirit. Continuum: Journal of Media \& Cultural Studies 15(2), 169-186.

Neal, J.A., Bergmann Lichtenstein, B.M. and Banner, D. (1999). Spiritual perspectives on individual, organizational and societal transformation. Journal of Organizational Change Management, 12(3) 175-185.

Paige, R.C. and Littrell, M.A. (2002). Craft Retailers' Criteria for Success and Associated Business Strategies. Journal of Small Business Management, 40(4), 314-331.

Porter, M. (1985). The Competitive Advantage: Creating and Sustaining Superior Performance. NY: Free Press.

Possamai, A. (2003). Alternative Spiritualities and the Cultural logic of Late Capitalism. Culture and Religion, 4(1) 31-45.

Redden, G. (2002). The New Agents: Personal transfiguration and radical privatization in New Age self-help. Journal of Consumer Culture, 2(1), 33-52.

Redden, G. (2005). The New Age: Towards a Market Model. Journal of Contemporary Religion, 20(2), 231-246.

Rindfleish, J. (2005). Consuming the Self: New Age Spirituality as "Social Product" in Consumer Society. Consumption, Markets and Culture, 8(4), 343-60.

Roof, W.C. (1999). Spiritual Marketplace. Baby Booomers and the Remaking of American Religion. Princeton NJ: Princeton University Press

Rose, S. (1998). An examination of the new age movement: Who is involved and what constitutes its spirituality. Journal of Contemporary Religion, 13(1), 5-22.

Starret, G. (1995). The Political Economy of Religious Commodities in Cairo. American Anthropologist, 97(1), 51-68.

Tanyi, R.A. (2002). Towards clarification of the meaning of spirituality. Journal of Advanced Nursing, 39(5), 500-509.

Thomas, P. (2009). Selling God/ saving souls. Religious commodities, spiritual markets and the media. Global Media and Communication, 5(1), 57-76.

Turner, B. (2004). Fundamentalism, Spiritual Markets and Modernity. Sociology, 38(1), 195-202.

Van Gelderen, M. and Jansen, P. (2006). Autonomy as a start-up motive. Journal of Small Business and Enterprise Development, 13(1), 23-32.

Zaidman, N. (2007a). The New Age Shop - Church or Marketplace? Journal of Contemporary Religion, 22(3), 361-74. 
Zaidman, N. (2007b). New Age Products in Local and Global Contexts. Culture and Religion: An Interdisciplinary Journal, 8(3), 255-270. 
Table 1: $\quad$ The for-profit provision of Spirituality goods and services

Provision

Store based retailing

Spirituality Fairs / Home based providers

On-line retailing

On-line service provider

Telephone / Text

Spirituality Retreats

\section{Comments}

Retailers offering spiritual goods and services through a store based offer. Typically outlets are not part of any multiple retail chain and comprise the owner - operator and a limited number of staff. Stores are often in a secondary shopping location and under 1,500 square feet.

Numerous small independent operators working from home and/or through spirituality fairs. In addition to general product providers specialist services are offered including Acupuncture, Aura Photography, Hypnotherapy, Palmistry and Tarot readings, Reflexology.

Retailers who provide goods and services online, some also have a physical presence either through stores, fairs or working from home. Consumers have access to both specialist providers as well as retailers whose assortment comprises a small spirituality offering. Channel includes local, national and international providers.

Overlap with the previous category, however their primary aim is to provide almost instant enlightenment by purchasing on-line Horoscopes, Psychic Readings, Dream Analysis, Cartomancy, Symbolon, Tarot, Divination. Some providers offer a small range of goods associated with their services e.g. horoscope pendants.

Typically premium rate pay per minute services that include psychic consultations, horoscopes and astrology readings. May be pre-recorded messages or one to one. For example, individual pre books a number of minutes with psychic and is given unique PIN number to access consultation. Services increasingly technology driven and extended into downloadable apps for mobile phones.

Dedicated locations that provide a wide range of spirituality activities including healing and counselling sessions, psychic consultations and Chakra balancing. Options range from short workshops to part time, certified programmes that require periods of attendance at the retreat. Many retreats have residential facilities. 
Table 2: $\quad$ Types of retail outlets offering Spirituality products

Category Products include:

Mind Body

Spirit

Occult/

Witchcraft

Holistic or

Complementary

Therapy

Fetish

Herbalist /

Homeopathy
New Age /

Angels, Aromatherapy, Bath, Body Piercing, Body \& Skincare, Books, Bumper Stickers, Calendars, Clothing, Crystals, Diaries \& Posters, Candles, Cards, CDs, Crystals, Fairies, Gods \& Goddesses, Herbs \& Resins, Incense, Fragrances, Jewellery, Magical Supplies, Mythical \& Magical Creatures, Tarot Readings, Palmistry and Mediumship, Oracles \& Divination, Witches \& Wizards

Athames, Chalices, Wands Cauldrons Altar Pieces, Incense \& Sticks Incense Powders Oils \& Oil Burners Herbs Roots and Resins Tarot, Crystal Balls, Pendulums Ouija Boards Scrying Mirrors \& Bowls, Candles and Holders, Altar Cloths Inks, Pens \& Seals, Boxes and Chests, Ritual Wear, God and Goddess Figures, Fairy Figurines, Dragons and Gargoyles, Egyptian Statues, Vamps, Runic Pendants, Jewellery and Charms, Magickal Pentagrams, Gems And Crystals, Second Hand Books, Blank Books of Shadows, Greetings Cards, Music

Pagan / Wiccan Aromatherapy, Crystals, Pagan market, (Jewellery, Athames, Chalices, Pendulums, Pentacles, Ritual tools, Runes, Spell Supplies, Spirit Boards, Tarot Cards, Wands) Angelic, (Cards, figures, smudging) Candles, Oils, Incense

Angels, Angel cards, Aura sprays, Buddhas, Beauty \& Spa treatments, Bio Energy, Meditation and Celtic CDs, Crystals and Tumble stones, Detox Spa, Holistic Therapies Hopi Ear Candling, Indian Head Massage, Pagan Goddess Pendants, Pamper Parties, Reiki, Reiki \& Crystal Workshops.

Leather, PVC, rubber, sexy underwear, collars, whips, chains; fantasy and role playing clothes, jewellery, ornaments, postcards hair braiding, fortune telling, crystal balls and tarot cards.

Glass Bongs, Books \& DVD's, Comedown and Hangover Cures, Essential Oils, Ethno-botanical Herbs, Grinders, Herbal Tinctures, Incense \& Holders, Pipes Chillums Glass \& Bubblers, Plant Feeders, Presses and Extraction Bubble Bags, Rolling Papers \& Blunts, Flavoured Papers \& Rolls, Rips \& Rolling Paper Tips.

Fairy / Fantasy / Fairy doors, fairies, dragons, angels, skulls, candles and incense, jewellery \& Gift store hair accessories, mugs \& glassware, party \& dress up, miniatures, keyrings \& stationery, books, cards \& CDs, trinket boxes, soaps \& perfumes, decorative art, lighting and steampunk.

Fair Trade / Clothing

Aromatherapy, Baby \& Children's Clothing, Candles and holders, fragrant sachets, gemstones, incense and holders, Kids Toys \& Gifts, Ladies Clothing, Men's Clothing, Musical Instruments, New Age books, Pendulums, Relaxing music, Tarot cards.

National Angel Cards, Magazines, Figurines

Retailers 


\footnotetext{
' While some authors provide separate definitions for New Age and Spirituality. They are used interchangeably in this paper.

ii Paganism is generally accepted as an umbrella term to represent any religion outside the JudeoChristian tradition. Wicca represents one pagan religion and was developed in the 20th century. Although its founding is generally credited to Gerald Gardner, it has no central authority and involves the worship of two deities, a mother goddess and horned god. In contrast, occultism is not tied to any specific religion and is concerned with the study of a reality that extends beyond pure reason. Occult practices have traditionally been portrayed as heretical and involving Satanism, black magic and demon worship. In practise there is no single overarching definition and occultists may practise alchemy, astrology and numerology.
} 